\title{
SELEKSI INDUK MATANG GONAD PADA SIPUT GONGGONG Laevistrombus turturella
}

\section{MATURE GONADAL BROODSTOCK SELECTION IN GONGGONG CONCH Laevistrombus turturella}

\author{
Muzahar $^{1 *}$, Muhammad Zairin Jr. ${ }^{2}$, Fredinan Yulianda ${ }^{3}$, \\ Muhammad Agus Suprayudi ${ }^{2}$, Alimuddin $^{2}$, \& Irzal Effendi ${ }^{2}$ \\ ${ }^{1}$ Program Studi Budidaya Perairan, FIKP-UMRAH, Tanjungpinang, 29115 \\ ${ }^{2}$ Departemen Budidaya Perairan, FPIK-IPB, Bogor, 16680 \\ ${ }^{3}$ Departemen Manajemen Sumberdaya Perairan, FPIK-IPB, Bogor, 16680 \\ *E-mail: mzet.oke@gmail.com
}

\begin{abstract}
Gonggong conch Laevistrombus turturella is a sea conch that has been consumed by many people in Kepulauan Riau Province so the population is expected to decline. One of the efforts to conserve conchs is through culture. Culture activities require the availability of the mature gonad broodstock. The aim of this study was to analyze the size of a mature gonadal of gonggong conch based on the shell length and the color of gonads, and to evaluate the effect of different temperature exposures in the speed of determining the sexual of broodstock. The conch shell length was measured by a caliper, then were broken to observe the gonad color. Data were analyzed by student t-test. The exposure treatments with water temperatures of $15^{\circ} \mathrm{C}(P 1), 20^{\circ} \mathrm{C}(P 2)$ and $30^{\circ} \mathrm{C}(P 3)$. Seven conch broodstocks were put into the aquarium according to the treatment, the duration of time the soft gonggong conch body came out of the shell was recorded. Data were analyzed with the Kruskal Wallis test. The results showed that the average length of the mature gonad gonggong conch broodstocks from MadongTanjungpinang sea were $63.449 \pm 5.352 \mathrm{~mm}$ (males) and $66.953 \pm 5.876 \mathrm{~mm}$ (females). Determination of the gonggong conch broodstock sexual can be accelerated with thermal shock on water temperature of $20^{\circ} \mathrm{C}$.
\end{abstract}

Keywords: effect of temperature, gonggong, size of a gonadal mature broodstock

\begin{abstract}
ABSTRAK
Siput gonggong Laevistrombus turturella merupakan siput laut yang banyak dikonsumsi masyarakat di Provinsi Kepulauan Riau sehingga populasinya diperkirakan menurun. Upaya pelestarian siput ini perlu dilakukan salah satunya dengan budidaya. Kegiatan budidaya memerlukan ketersediaan induk matang gonad. Tujuan penelitian ini adalah menganalisis ukuran induk siput gonggong matang gonad berdasarkan panjang cangkang dan warna gonad, serta mengevaluasi pengaruh paparan suhu berbeda terhadap kecepatan penentuan jenis kelamin induk. Panjang cangkang siput gonggong diukur dengan jangka sorong, kemudian dipecahkan untuk mengamati warna gonadnya. Data dianalisis dengan student t-test. Perlakuan paparan suhu air $15^{\circ} \mathrm{C}(\mathrm{P} 1), 20^{\circ} \mathrm{C}(\mathrm{P} 2)$, dan $30^{\circ} \mathrm{C}(\mathrm{P} 3)$. Tujuh ekor induk siput gonggong dimasukkan ke dalam akuarium sesuai perlakuan, durasi waktu keluar tubuh lunak siput gonggong dari cangkang dicatat. Data dianalisis dengan uji Kruskal Wallis. Hasil penelitian menunjukkan ukuran rata-rata panjang cangkang induk siput gonggong matang gonad dari laut Madong-Tanjungpinang adalah 63,449 $\pm 5,352 \mathrm{~mm}$ (jantan) dan 66,953 $\pm 5,876 \mathrm{~mm}$ (betina). Penentuan jenis kelamin siput gonggong dapat dipercepat dengan pemberian kejutan suhu dengan suhu air $20^{\circ} \mathrm{C}$.
\end{abstract}

Kata kunci: gonggong, pengaruh suhu, ukuran induk matang gonad 


\section{PENDAHULUAN}

Jenis siput laut yang bernilai ekonomis tinggi dan banyak dikonsumsi oleh masyarakat di Provinsi Kepulauan Riau (Kepri) khususnya Kota Tanjungpinang adalah siput gonggong. Harga gonggong hidup dengan ukuran 27-32 ekor/kg adalah Rp35.000,00 (Muzahar et al., 2019). Ada lima varian morfologi siput ini yang dapat ditemukan hidup di perairan laut MadongTanjungpinang. Analisis molekuler dengan sekuen gen histone H3 menunjukkan kelima varian adalah spesies $L$. turturella dengan kerabat terdekat Strombus canarium (Muzahar et al., 2018). Eksploitasi terhadap siput gonggong semakin intensif dilakukan oleh para nelayan sehingga populasinya menurun (Muzahar \& Hakim, 2018). Populasi siput gonggong perlu dilestarikan diantaranya melalui budidaya. Budidaya siput gonggong sebagaimana banyak golongan gastropoda lainnya di Indonesia belum berkembang sampai saat ini. Cob et al. (2009a) melakukan penetasan telur siput gonggong yang diambil dari alam di laboratorium, namun tingkat keberhasilannya masih rendah. Teknologi reproduksi siput ini masih belum benar-benar dikuasai. Pembenihan merupakan salah satu kegiatan dalam budidaya biota akuatik. Produksi benih siput gonggong sangat ditentukan oleh keberhasilan proses pemijahan. Pemijahan siput gonggong tidak akan berhasil tanpa ketersediaan induk matang gonad dan siap dipijahkan. Sebelum induk siput gonggong dipijahkan dilakukan penentuan jenis kelamin induk. Penentuan jenis kelamin induk adalah langkah pertama untuk melakukan reproduksi. Oleh karena itu, cara praktis menentukan jenis kelamin induk siput ini sangat penting.

Ukuran panjang cangkang total merupakan indikator penting tingkat kematangan gonad pada gastropoda laut (Abbot, 1960). Ukuran panjang cangkang total induk siput gonggong yang matang gonad dari perairan laut MadongTanjungpinang belum diketahui. Selain itu, penentuan jenis kelamin induk siput gonggong jantan dan betina secara cepat dan tepat berdasarkan morfologi cangkang sulit dilakukan, karena kemiripan bentuk cangkang dan tubuh siput gonggong yang keberadaannya dalam cangkang. Teknik penentuan jenis kelamin induk siput gonggong yang cepat dan tepat belum pernah dilaporkan sehingga perlu dikaji, misalnya melalui paparan suhu air. Cangkang siput gonggong berfungsi sebagai alat pelindung terhadap bahaya dari lingkungan eksternal bagi gonggong. Bentuk cangkang siput gonggong pada pertumbuhannya memperlihatkan perputaran spiral dengan sudut $180^{\circ}$, pada kondisi demikian hewannya akan kembali ke posisi semula (Suwignyo et al., 2005). Siput gonggong (L. turturella) tergolong hewan dioecious karena organ reproduksinya terdapat pada individu yang terpisah. Siput gonggong jantan memiliki penis dan betina memiliki saluran telur. Warna gonad matang pada siput betina adalah krem, dan pada siput jantan berwarna oranye (Cob et al., 2008). Siput ratu ( $S$. gigas) dewasa memiliki jenis kelamin yang terpisah dan matang secara seksual setelah berusia sekitar 4 tahun, dengan nisbah kelamin 1:1 (Davis, 2005). Gastropoda umumnya melakukan kopulasi dan pembuahan di dalam induk betina (Cob et al., 2008). Informasi tentang teknik penentuan jenis kelamin induk secara cepat dan tepat dalam pemijahan siput gonggong belum dilaporkan. Berdasarkan uraian di atas, penelitian ini perlu dilakukan.

Tujuan penelitian ini adalah (1) menganalisis ukuran induk siput gonggong (L. turturella) matang gonad dari laut Madong-Tanjungpinang berdasarkan panjang cangkang total dan warna gonad, dan (2) mengevaluasi pengaruh paparan suhu berbeda terhadap kecepatan penentuan jenis kelamin induk. 


\section{METODE PENELITIAN}

\subsection{Waktu dan Tempat Penelitian}

Penelitian ini dilaksanakan pada bulan Januari-April 2019 di Marine Biology Laboratory, FIKP-Universitas Maritim Raja Ali Haji, Tanjungpinang. Siput gonggong yang digunakan dalam penelitian ini diperoleh dari 39 titik sampling di laut Madong-Tanjungpinang pada koordinat 097'37"-098'30,83" LS dan 10443'38,63"10448'19" BT. Perairan laut MadongTanjungpinang merupakan daerah tangkapan siput gonggong yang memiliki tipe substrat lumpur berpasir yang ditumbuhi lamun dengan kepadatan sedang (Muzahar et al., 2019).

\subsection{Penelitian Tahap I}

\subsubsection{Penyiapan dan Penanganan Siput Gonggong}

Pengambilan siput gonggong dilakukan saat surut terendah. Siput gonggong dikoleksi secara manual dengan tangan. Lokasi sampling ditentukan secara purposive sampling. Pada lokasi sampling dengan kedalaman lebih dari satu meter dilakukan penyelaman. Siput gonggong yang diperoleh dicuci bersih dengan air laut, kemudian dimasukkan dalam kantong plastik yang telah diberi label. Siput gonggong dibawa ke laboratorium untuk dianalisis. Panjang cangkang total semua gonggong diukur menggunakan jangka sorong digital berpresisi 0,001 mm mengacu metode Cob et al. (2009b). Analisis ukuran induk siput gonggong matang gonad mengacu metode Cob et al. (2008) yaitu berdasarkan warna gonad dan panjang cangkang. Gonad induk jantan berwarna oranye dan gonad betina berwarna krem. Cangkang siput gonggong dipecahkan secara hati-hati dengan palu supaya organ dalamnya tidak rusak. Warna gonad, saluran telur, dan penis diamati secara makroskopis untuk validasi penentuan jenis kelamin induk gonggong.

\subsubsection{Parameter Uji dan Analisis data}

Parameter yang diukur adalah panjang cangkang total rata-rata dari 118 ekor siput gonggong yang terdiri atas 60 ekor jantan dan 58 ekor betina. Siput gonggong matang gonad dicirikan warna gonadnya oranye pada individu jantan dan krem pada individu betina, serta berwarna hijau pada individu yang belum matang gonad. Data dianalisis secara statistik dengan uji-t student $t$-test dengan bantuan komputer dan software SPSS versi 16.

\subsection{Penelitian Tahap II}

\subsubsection{Rancangan Percobaan}

Penelitian ini menggunakan rancangan acak lengkap dengan tiga perlakuan dan tiga ulangan terdiri atas paparan suhu air $15^{\circ} \mathrm{C}(\mathrm{P} 1)$, suhu air $20^{\circ} \mathrm{C}$ (P2), dan suhu air $30^{\circ} \mathrm{C}$ (P3). Sebanyak 63 ekor siput gonggong jantan dan betina berukuran 69,41 $\pm 3,60$ disiapkan untuk ketiga perlakuan. Masing-masing tujuh ekor induk siput gonggong dimasukkan langsung ke dalam akuarium sesuai perlakuan. Posisi cangkang siput gonggong diatur sedemikian rupa sehingga bagian bawah bibir luar cangkang menghadap ke pengamat (Figure 1).

Penis atau saluran telur diamati ketika siput gonggong mengeluarkan tubuh lunaknya dari dalam cangkang. Hasil pengamatan untuk validasi jenis kelamin

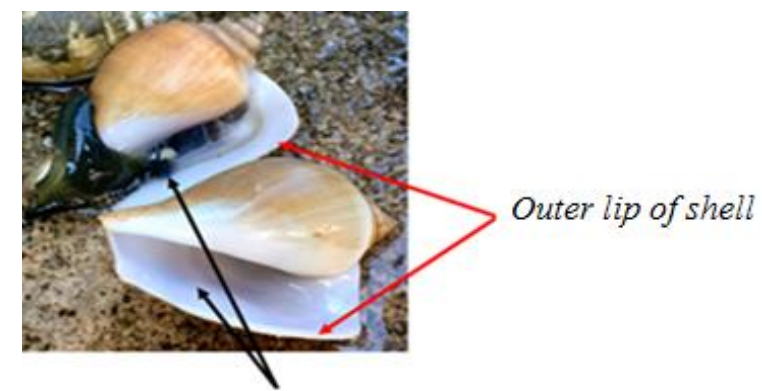

The direction of the observer's eye

Figure 1. The position of the gonggong conch when observed for its secondary genital organs. 
siput gonggong dilakukan dengan cara cangkang siput gonggong dipecahkan secara hati-hati dengan palu. Warna gonad dari masing-masing siput gonggong yang telah dipecahkan diamati satu persatu. Gonad induk siput gonggong jantan matang kelamin berwarna oranye dan gonad induk siput gonggong betina matang gonad berwarna krem.

\subsubsection{Penyiapan Akuarium}

Sebanyak tiga unit akuarium berukuran $40 \mathrm{~cm} \times 30 \mathrm{~cm} \times 40 \mathrm{~cm}$ diisi $10 \mathrm{~L}$ air laut bersalinitas $30 \mathrm{ppt}$ dan masingmasing dilengkapi dengan termomoter alkohol disiapkan untuk wadah percobaan. Ketiga akuarium yang sama digunakan kembali untuk pengamatan berikutnya sesuai jumlah ulangan dalam perlakuan yaitu tiga ulangan. Akuarium ditempatkan dalam laboratorium berpendingin ruangan (air conditioner, AC) pada suhu $25^{\circ} \mathrm{C}$. Ice gel dimasukkan ke dalam akuarium sesuai perlakuan untuk menurunkan suhu menjadi $15^{\circ} \mathrm{C}$ dan $20^{\circ} \mathrm{C}$.

\subsubsection{Parameter Uji dan Analisis Data}

Parameter yang diamati adalah durasi waktu saat penis atau saluran telur terlihat bersamaan dengan keluarnya tubuh lunak siput gonggong. Data yang diperoleh dianalisis secara statistik non parametrik dengan uji Kruskal Wallis dengan bantuan komputer dan software SPSS versi 16.

\section{HASIL DAN PEMBAHASAN}

\subsection{Hasil}

\subsubsection{Ukuran Induk Siput Gonggong Madong-Tanjungpinang}

Sebanyak 278 ekor siput gonggong dengan berbagai ukuran berhasil dikoleksi dari laut Madong-Tanjungpinang. Sebanyak 118 ekor siput gonggong ditemukan matang gonad, terdiri atas 60 ekor siput gonggong jantan dan 58 ekor siput gonggong betina, sisanya siput gonggong jantan dan betina stadia muda dan juvenil. Ukuran rata-rata panjang cangkang siput gonggong jantan dan betina matang gonad yang diperoleh ditampilkan pada Figure 2.

Panjang cangkang induk siput gonggong jantan matang gonad adalah $63,448 \pm 5,352 \mathrm{~mm}$, lebih rendah daripada ukuran induk gonggong betina matang gonad $(66,953 \pm 5,876 \mathrm{~mm})$. Hasil analisis uji-t menunjukkan adanya perbedaan signifikan di antara kedua jenis kelamin $(\mathrm{P}<0,05)$.

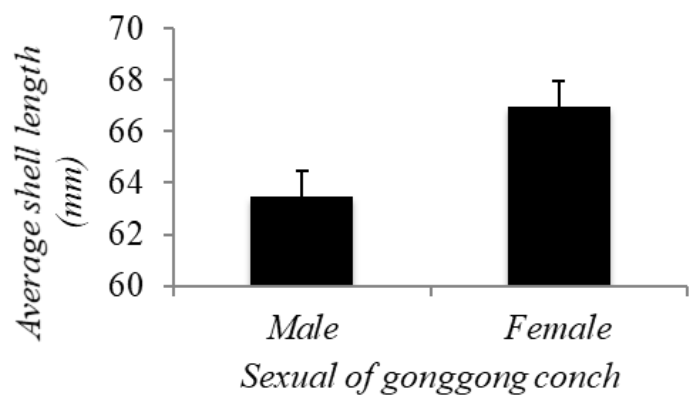

Figure 2. Shell length of male and female gonggong conch of mature gonads.

\subsubsection{Pengaruh Paparan Suhu Air Berbeda pada Penentuan Jenis Kelamin Siput Gonggong}

Hasil pengamatan paparan suhu air yang berbeda terhadap kecepatan induk siput gonggong mengeluarkan tubuh dari cangkangnya disajikan pada Figure 3. Ciri seksual sekunder berupa penis pada induk jantan dan saluran telur pada betina serta proboscis dan tangkai mata yang berhasil diamati ditampilkan pada Figure 4.

Jumlah siput gonggong yang mengeluarkan tubuh dari cangkangnya setelah diberi paparan suhu berbeda adalah 2 ekor $(9,52 \%)$ pada perlakuan P1, 11 ekor $(52,38 \%)$ pada $\mathrm{P} 2$ dan 14 ekor $(66,67 \%)$ pada P3. Terdapat perbedaan waktu rata-rata siput gonggong mengeluarkan tubuhnya dari cangkang, berturut-turut dari yang paling cepat ke paling lambat, yaitu $2,45 \pm 1,36$ menit pada suhu $20^{\circ} \mathrm{C}$ (P2), $11,1 \pm 14,16$ menit pada suhu $15^{\circ} \mathrm{C}(\mathrm{P} 1)$ dan $18,69 \pm 2,02$ menit pada suhu $30^{\circ} \mathrm{C}(\mathrm{P} 3)$. Hasil uji Kruskal Wallis menunjukkan ada perbedaan nyata di antara perlakuan $(\mathrm{P}<0,05)$. 
Organ kelamin primer (gonad) siput gonggong yang matang setelah dipecahkan tampak berwarna oranye pada individu jantan, dan berwarna krem pada individu betina, diperlihatkan pada Figure 5.

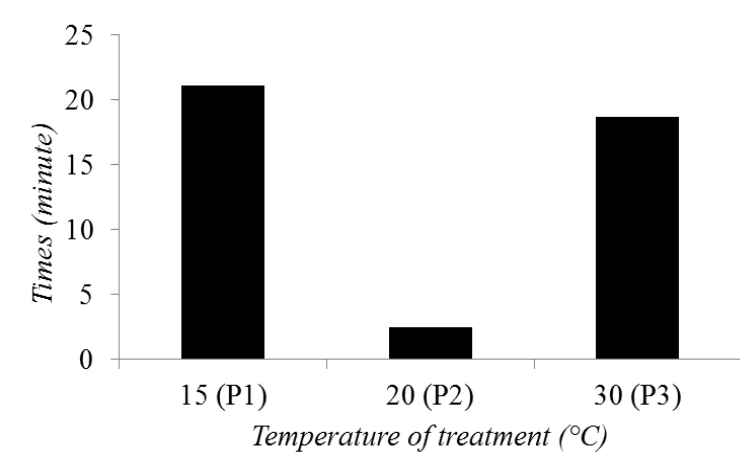

Figure 3. The average time for gonggong conchs to expel the body from its shell after exposure to different water temperatures.

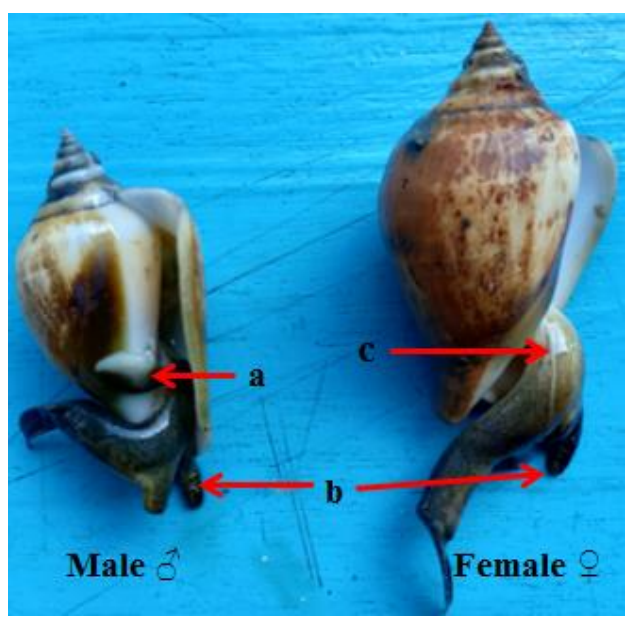

Figure 4. The penis in male gonggong conch (a), proboscis (b), egg groove in female gonggong conch (c).

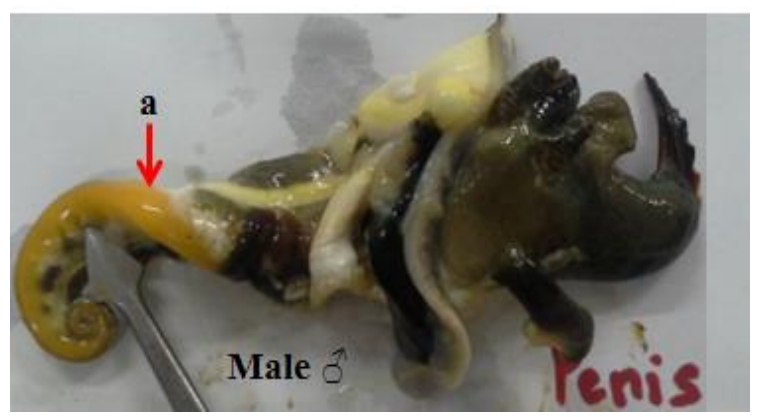

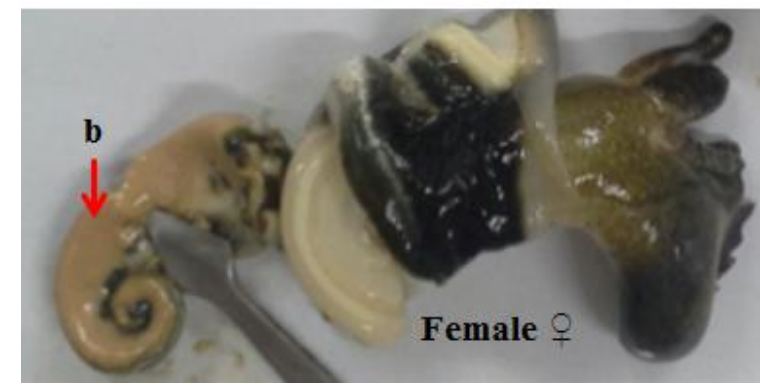

Figure 5. The mature gonad in male gonggong conchs are orange (a), the mature gonad in female gonggong conchs are cream (b).

\subsection{Pembahasan}

Ukuran panjang cangkang siput gonggong jantan matang gonad adalah $63,449 \pm 5,352 \mathrm{~mm}$, lebih kecil $(\mathrm{P}<0,05)$ dibanding induk betina matang gonad $(66,953 \pm 5,876 \mathrm{~mm})$. Hasil ini didukung oleh Abbott (1960), bahwa penentuan ukuran siput matang gonad siput Strombidae didasarkan pada panjang cangkang sebagai salah satu karakter utama yang paling berkorelasi dengan kematangan gonad genus ini. Beberapa jenis siput Strombidae lainnya menunjukkan ukuran cangkang siput jantan lebih kecil dari siput betina. Ukuran induk siput $S$. canarium jantan matang gonad adalah 54,67 $\pm 3,76 \mathrm{~mm}$ dan betina $55,56 \pm 3,72 \mathrm{~mm}$ (Cob et al., 2008), siput ratu (S. gigas) jantan $234 \mathrm{~mm}$ dan betina $249 \mathrm{~mm}$ (Poveda \& Cardenas, 2006). Cangkang siput Strombidae berhenti tumbuh panjang setelah mencapai dewasa (Abbott, 1960). Ketika siput gonggong telah dewasa, pertumbuhan panjang minimal dan pertumbuhan cangkang berikutnya dalam bentuk penebalan cangkang dan bibir luar (Dolbeth et al., 2005).

Paparan suhu air berbeda memberikan pengaruh yang berbeda nyata terhadap kecepatan keluarnya tubuh lunak siput gonggong dari cangkangnya di antara ketiga perlakuan. Hasil pengamatan menunjukkan bahwa paparan suhu air $20^{\circ} \mathrm{C}$ merupakan suhu rata-rata tercepat $(2,45$ menit) bagi siput gonggong mengeluarkan 
tubuhnya. Kondisi ini memudahkan dalam mengamati alat kelamin seksual sekunder siput gonggong dibanding perlakuan lain. Pemberian paparan suhu media $20^{\circ} \mathrm{C}$ yang lebih rendah (thermal shock) dari suhu normal perairan $30^{\circ} \mathrm{C}$ diduga mengakibatkan terjadinya rangsangan pada saraf kaki dan saraf tubuh siput gonggong sehingga mendorong siput gonggong mengeluarkan tubuhnya. Pernyataan ini didukung oleh pendapat Kozloff (1989), bahwa golongan gastropoda memiliki saraf kaki dan saraf organ dalam tubuh. Suhu mempengaruhi metabolisme dan berperan penting dalam pengaturan aktivitas suatu biota. Adanya perubahan suhu menjadi isyarat bagi suatu biota untuk memulai atau mengakhiri berbagai aktivitas. Rentang suhu yang sesuai untuk fisiologis umumnya lebih rendah dari batas toleransi maksimumnya (Nybakken, 1992; Islami, 2013). Sebagian besar spesies yang hidup di lautan bersifat stenothermal. Variasi suhu harian sangat mempengaruhi metabolisme dan aktivitas spesies. Pernyataan di atas terbukti dengan adanya pemberian kejutan suhu (thermal shock) dalam penelitian ini. Gonad matang pada siput gonggong ( $L$. turturella) berwarna oranye pada individu jantan dan berwarna krem pada individu betina mirip dengan warna gonad pada siput $S$. canarium (Cob et al., 2008) dan siput ratu (S. gigas) (Delgado \& Glazer, 2008).

\section{KESIMPULAN}

Ukuran rata-rata panjang cangkang total siput gonggong (L. turturella) matang gonad dari laut Madong-Tanjungpinang adalah 63,449 $\pm 5,352 \mathrm{~mm}$ (jantan) dan $66,953 \pm 5,876 \mathrm{~mm}$ (betina). Penentuan jenis kelamin siput gonggong dapat dipercepat dengan perlakuan paparan kejutan suhu (thermal shock) dengan suhu air $20^{\circ} \mathrm{C}$.

\section{UCAPAN TERIMA KASIH}

Riset $\begin{gathered}\text { Penelitian ini didanai oleh Direktorat } \\ \text { Pengabdian }\end{gathered}$ Kemenristekdikti RI dengan skim Penelitian Disertasi Doktor (PDD) dengan nomor kontrak 064/SP2H/LT/DRPM/2018. Terima kasih disampaikan kepada Direktur DRPM Kemenristekdikti, Rektor UMRAH, Kepala LP3M UMRAH, Dekan FIKP UMRAH, Kepala Marine Biology Laboratory FIKPUMRAH atas bantuan fasilitas dan dukungannya dalam penelitian ini, Zulpikar, Hamzah, Rohayati, Siti Nurbaya, Budi Primulia, Hary Wibowo, Agus Muslim serta semua pihak yang telah membantu Penulis.

\section{DAFTAR PUSTAKA}

Abbott, R.T. 1960. The genus Strombus in the Indo-Pacific. Indo-Pacific Mollusca, 1: 33-144. https://www.biodiversitylibrary.org/p age/49824288\#page/35/mode/1up

Cob, Z.C., A. Arshad, M.A. Ghaffar, J.S. Bujang, \& W.L.W. Muda. 2009a. Development and growth of larvae of the dog conch (Strombus canarium) (Mollusca: Gastropoda), in the laboratory. J. of Zoological Studies, 48(1): 1-11.

http://zoolstud.sinica.edu.tw/Journals/ 48.1/1.pdf

Cob, Z.C., A. Arshad, J.S. Bujang, \& M.A. Ghaffar. 2009b. Species description and distribution of Strombus (Mollusca: Strombidae) in Johor Straits and its surrounding areas, $J$. Sains Malaysiana, 38(1): 39-46.

Cob, Z.C., A. Arshad, M.A. Ghaffar, \& J.S. Bujang. 2008. Sexual maturity and sex determination in Strombus canarium. J. Biological Science, 8(3): 616-621.

https://doi.org/10.3923/jbs.2008.616. 621 
Davis, M. 2005. Species Profile: Queen Conch (Strombus gigas). SRAC Publication, 7203. 12 p.

Dolbeth, M., A.I. Lillebo, P.G. Cardoso, S.M. Ferreira, \& M.A. Pardal. 2005. Annual production of estuarine fauna in different environmental conditions: An evaluation of the estimation methods. J. Experimental Marine Biology and Ecology, 326: 115-127.

Delgado, G. \& R. Glazer. 2008. Collections of conch tissue, water, and sediment. In: Glazer R. (ed). Anthropogenic effects on queen conch reproductive development in South Florida. A Final Report. Ocean Springs Press. Florida. 3-5 pp.

Kozloff, E.N. 1989. Invertebrates. New York (US): Saunders College Publishing. $866 \mathrm{p}$.

Islami, M.M. 2013. Pengaruh suhu dan salinitas terhadap bivalvia. J. Oseana, 38(2): 1-10.

http://lipi.go.id/publikasi/pengaruh-

suhu-dan-salinitas-terhadapbivalvia/16917

Muzahar, M. Zairin Jr., F. Yulianda, M.A. Suprayudi, Alimuddin, \& I. Effendi. 2019. Fisiologi Reproduksi pada Pematangan gonad dan pemijahan siput gonggong (Laevistrombus turturella) dari Tanjungpinang di Wadah Budidaya. Disertasi Doktor. Institut Pertanian Bogor. Bogor. 101 p.

Muzahar, M. Zairin Jr., F. Yulianda, M.A. Suprayudi, Alimuddin, \& I. Effendi.
2018. The phenotype comparison and genotype analysis of five Indonesian Laevistrombus sp. variants as a basis of species selection for aquaculture. AACL Bioflux, 11(4): 1164-1172. http://www.bioflux.com.ro/docs/2018 .1164-1172.pdf

Muzahar \& A.A. Hakim. 2018. Spawning and development of dog conch Strombus sp. larvae in the laboratory. J. Ilmu dan Teknologi Kelautan Tropis, 10(1): 209-216. http://doi.org/10.29244/jitkt.v10i1.18 607

Nybakken, J.W. 1992. Biologi Laut: Suatu Pendekatan Ekologi. Eidman H.M, (penterjemah). Koesoebiono, D.G. Bengen, M. Hutomo, dan S. Sukardjo. Penerbit Gramedia. Jakarta. $459 \mathrm{p}$.

Poveda, O.H.A. \& E.R.B. Cardenas. 2006. Size at sexual maturity in the queen conch (Strombus gigas) from Colombia. Bo Invest Mar Cost, 35: 223-233.

http://www.scielo.org.co/pdf/mar/v35 n1/v35n1a13.pdf

Suwignyo, S., B. Widigdo, Y. Wardiatno, \& M. Krisanti. 2005. Avertebrata air jilid 1. Penebar Swadaya. Jakarta. 204 p.

Received : 30 December 2019

Reviewed :04 February 2020

Accepted : 25 April 2020 
